\title{
Visualization method for volume void fraction measurements in gas-liquid two-phase flows of a water turbine outlet channel
}

\author{
R. Klasinc ${ }^{1}$, M. Hočevar ${ }^{2}$, T. Baicar ${ }^{2}$ \& B. Šrok ${ }^{2}$ \\ ${ }^{I}$ Graz University of Technology, Department for Hydraulic Structures \\ and Water Resources Management, Austria \\ ${ }^{2}$ University of Ljubljana, Faculty for Mechanical Engineering, Slovenia
}

\begin{abstract}
The Pelton turbines are the part of the pump-storage scheme that is working under permanent backpressure conditions. The knowledge of air-absorbing and degassing in the vessel which follows the turbine chamber is important for the safe and economical working of the turbine. In the case of so called hydraulic short circuit the influence of air bubbles for the safe operation of turbines and pumps is very important. To estimate the volume void fraction in two-phase flow, the measurement method was developed, which is based on the computeraided visualization. Acquisition of flow images by a fast video camera followed by the computer processing of the acquired images enables the determination of the void fraction via the average value of grey level intensity of the acquired flow images. A relationship between the void fracture and the average grey level intensity was obtained through calibration of the measurement system. Simultaneous measurements with the other measurement method revealed suitability and applicability of the visualization method in a real industrial environment such as a tailwater channel of a Pelton turbine. Apart from that, a study revealed that by further processing the images a number of other important information on the flow, such as bubble size and shape, average bubble direction and velocity, can be obtained by the described method.
\end{abstract}

Keywords: air-water two-phase flow, computer-aided visualization, tailwater channel. 


\section{Introduction}

The void fraction, which denotes the phase distribution in multiphase flows, is one of the most important parameters of two-phase flows, especially in twophase gas-liquid systems. Measurement of the void fraction is essential in many industrial applications in order to define or monitor the parameters such as pressure drop, heat transfer rate or any other transfer mechanism or process between the flow and the confining walls or between phases themselves within the two-phase flow. There are many intrusive as well as non-intrusive methods, which are commonly used to measure void fraction in multiphase flows. Some of the most popular are the method of gamma rays absorption (Stahl and von Rohr [9]), the method of magnetic resonance (Daidzic et al., [1]), tomography and impedance methods (Dong et al., [2]; Jaworek et al., [6]; Huang et al., [5]), double sensor probes (Hogsett and Ishii, [4]; Hibiki and Ishii, [3]) or isokinetic (suction) methods (Mayr and Arch, [7]).

It is sometimes hard to identify the most appropriate method for measuring the void fraction. As far as industrial measurements are concerned, there is often a need to conduct fast yet accurate enough measurements in harsh industrial conditions, e.g. in purification facilities, waste water processing, powerplants etc. The above-mentioned methods are often not particularily suitable for such measurements, for they are either meant to be used in laboratory conditions and are not robust enough or they demand extensive (and expensive) preparations or they are simply too complex or clumsy for quick and easy handling. The visualization method, which is described below, tends to fill such a gap, for it is developed mainly to be used in the industrial environment.

\section{Description of the system}

The measurement system for the volume void fraction measurements in open channels is based on the acquisition of the images of the water flow using the high speed camera. The measurement system consists of the the following main parts, which are pointed out in Fig. 1 as well:

- black \& white industrial high speed camera SONY XC HR50 with power supply $12 \mathrm{~V}$,

- lens cosmicar / pentax H1212B 12 mm F 1.2 with close up lenses $6+5 \mathrm{D}$,

- $\quad$ illumination LED CCS LDL-TP-51x51 12V, 4.4W,

- cables for connection of the camera to the framegrabber and power supply of length $30 \mathrm{~m}$,

- $\quad$ water resistant measurement probe with chassis for the camera, lens and illumination,

- $\quad$ framegrabber National Instruments PCI NI 1409,

- base software package National Instruments Labview together with Vision module,

- $\quad$ personal computer, monitor, keyboard and mouse. 


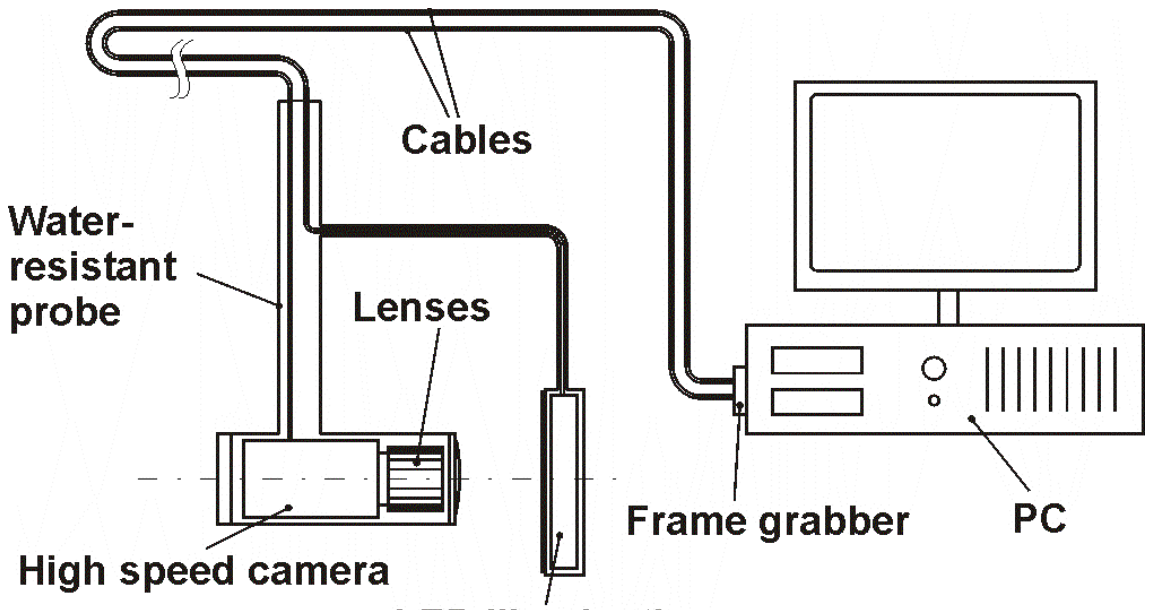

\section{LED illumination}

Figure 1: Schematics of the measurement system.

The spatial resolution of the camera is $640 \times 480$ pixels. Each pixel corresponds to $0.04185 \mathrm{~mm}$, calculated in the center of gravity of the volume part between the camera and the illumination. The acquisition frequency of the camera is set to $60 \mathrm{~s}^{-1}$. The black \& white resolution is 8 bits or 256 grey levels.

Void fraction measurement by the described system is based on the average grey level intensity of the images of the flow in a measurement volume between the camera lens and the illumination source. As a type of illumination we have selected background illumination, therefore images of the illuminated water have a high value of grey level intensity, which depends on the water turbidity and is close to white (grey level intensity 1). On the other hand, the illuminated air bubble has a very low value of the grey level intensity along its circumference, which is close to black (grey level intensity 0) - Fig. 2.

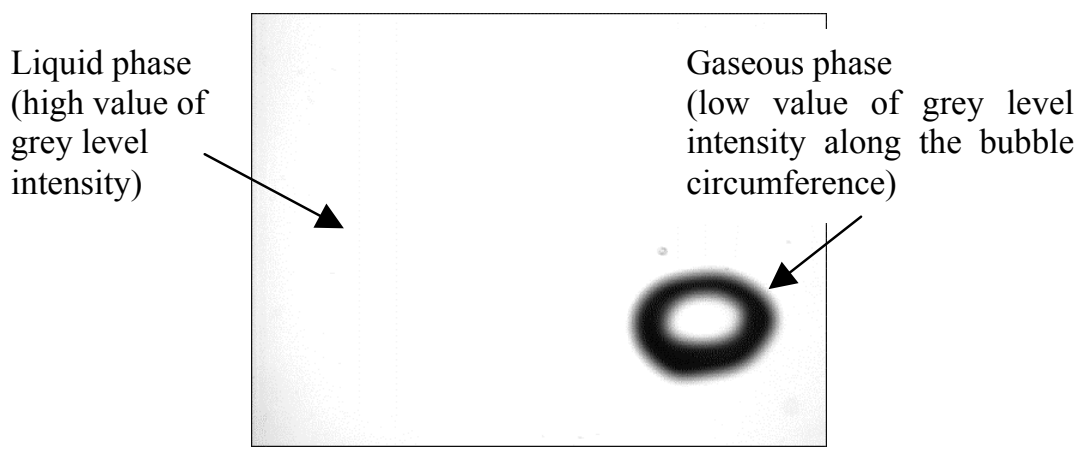

Figure 2: $\quad$ Image of an air bubble in liquid (water). 
Average grey level intensity $(A)$ can be obtained from $N$ images by eqn. 1 (Trdič et al., [10]):

$$
A=\frac{1}{N} \sum_{i=1}^{N}\left(\frac{1}{n} \sum_{j=1}^{n} E_{j}\right),
$$

where $E$ denotes the grey level intensity of the $j$-th pixel of the image. $n$ denotes the number of all pixels in a single image. The variable $E$ as well as the variable $A$ have values between 0 (black) and 1 (white).

A calibration procedure has to be carried out in order to obtain the relationship between the average grey level intensity $A$ and the void fraction $\alpha$.

\section{Calibration}

The calibration of the developed measurement system for volume air void fraction measurements in water was performed using newly manufactured calibration device (Fig. 3). The calibration procedure is based on the measurement of the increase of the height of the water upper surface in the water column when bubbles are injected in the flow.

The calibration device consisted of vertical vessel of square cross section, openings for inclusion of measurement system, air supply in the bottom part of the vessel through porous inserted block, and measurement slit for measurement of water level in the vessel.

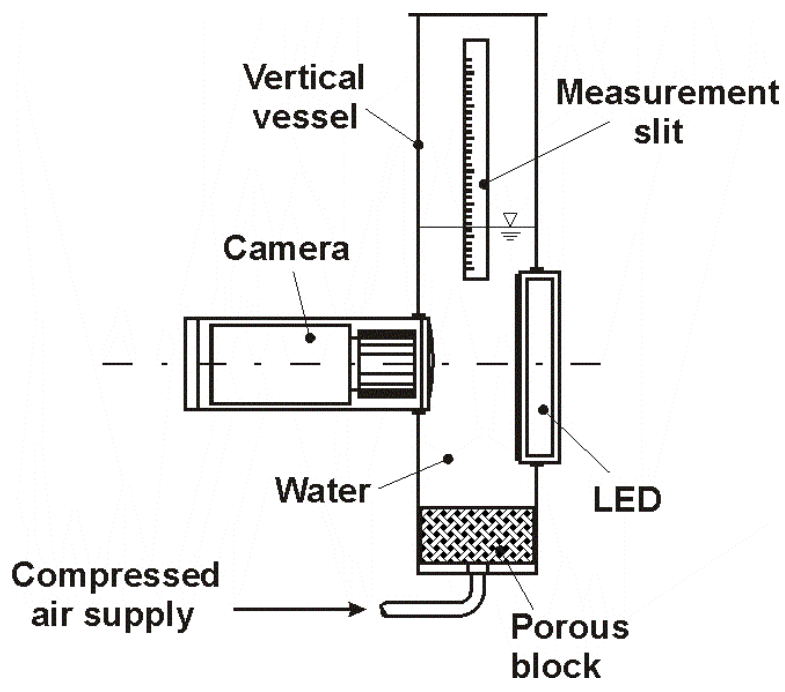

Figure 3: Configuration of the calibration device. 
The calibration device enables immediate calibration of the measurement system in the form of functional relationship between the water height level and void fraction of the gaseous phase in the liquid phase, expressed with the variable $\alpha$ as defined by the expressions:

$$
\begin{gathered}
\alpha=\frac{\dot{V}_{z}}{\dot{V}_{z}+\dot{V}_{v}} \\
\rho=\rho_{z} \alpha+(1-\alpha) \rho_{v} \\
\alpha=\frac{\rho_{v}\left(1-\frac{H_{o}}{H}\right)}{\left(\rho_{v}-\rho_{z}\right)},
\end{gathered}
$$

where $\rho_{z}$ and $\rho_{v}$ denote air and water density, respectively, $H_{o}$ denotes the water level before the inclusion of gaseous phase, and $H$ denotes the water level during the inclusion of gaseous phase.

The calibration procedure was performed using the assumption that the two phase bubble flow is homogeneous and that there is the same distribution of bubbles size in the calibration device and in the field experiment. The effect of compressibility was considered as well.

Calibration results are given in Figs. 4 and 5 using presumed functional relationships. These enable calculation of the air void fraction in the test section in dependence on the measured grey level intensity. Figs. 4 and 5 show monotonous functional relationship between the both variables. The non-linear functional relationship can be represented by exponential dependence in the form:

$$
A=k_{1} e^{-k_{2} \alpha}
$$

where $A$ denotes measured grey level intensity, $\alpha$ is the volume air void fraction in the control volume, whereas $\mathrm{k}_{1}$ and $\mathrm{k}_{2}$ denote experimentally derived constants.

The inverse functional relationship can be determined and expressed in the form:

$$
\alpha=k_{3} \ln (A)+k_{4},
$$

where $k_{3}$ and $k_{4}$ are experimentally derived constants.

The value of the correlation coefficient $(r)$ between measured values and the trend line function (y) for $\alpha$ (Fig. 4) and $A$ (Fig. 5) is $r^{2}=0.99$ in both cases. It should be emphasized that for proper determination of functional relationship between the air volume void fraction and grey level intensity a correction due to 
turbidity of the water should be performed where necessary on site of the measurement. In some cases a correction due to different bubble sizes as well as the effect of bubbles coalescence should also be performed. For the present work the calibration was performed using clear potable water.

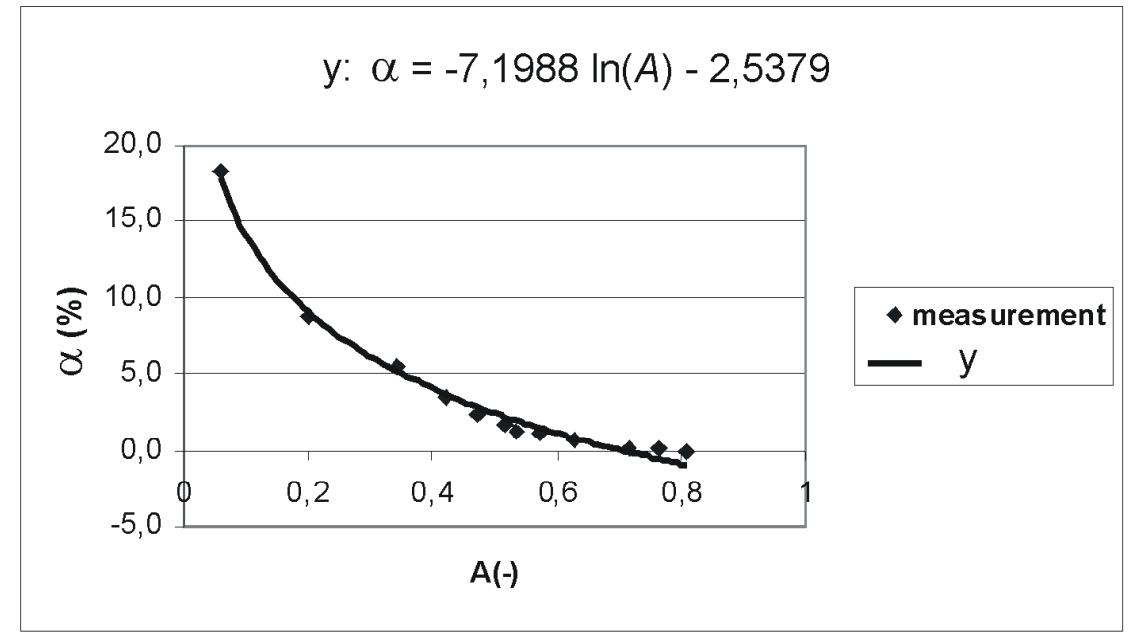

Figure 4: Functional dependence of volume air void fraction on measured grey level intensity.

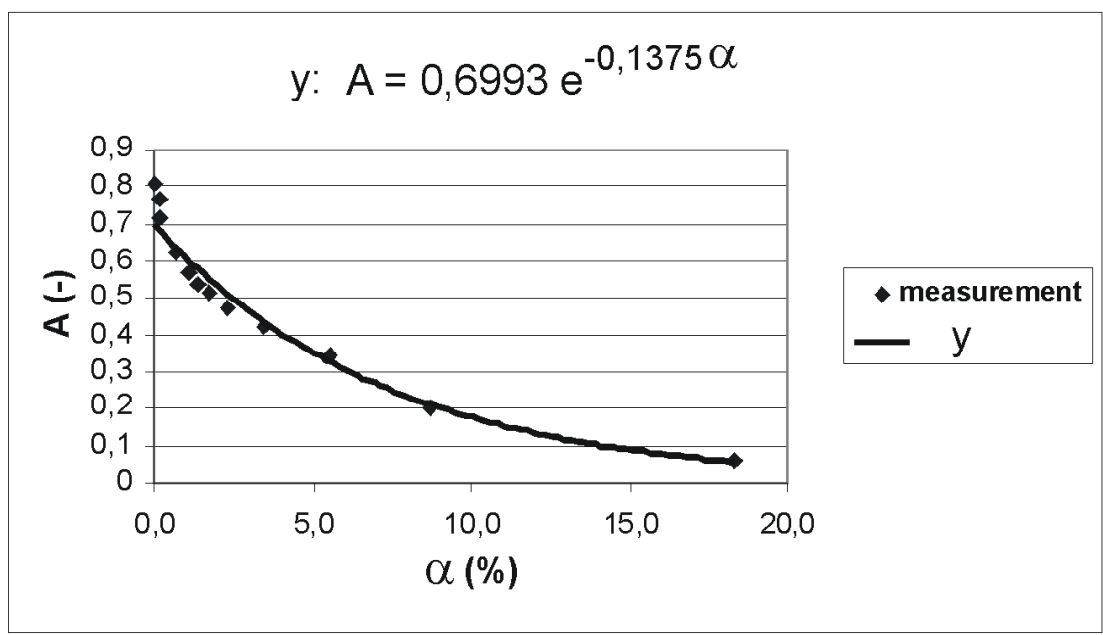

Figure 5: Functional dependence of grey level intensity on volume air void fraction. 


\section{Measurement setup}

Void fraction measurements were performed in the outlet channel of the Koralpe hydroelectric plant (Drau river) according to the order placed by the Technische Universität Graz (TUG). Schematics of the measurement points selection is shown in Fig. 6.

Eight transverse measurement planes were selected with distance from the turbine axis shown in table 1 . In every measurement plane six measurement points were selected with vertical positions shown in table 2 .

The positioning was provided by servo positioning system from TUG (Mayr and Arch, [7]). Water depth in the channel was $1.63 \mathrm{~m}$.

For the transverse measurement planes e to $\mathrm{h}$ in the middle position, the height of the measuring point 6 at the vertical position 6 is $1.50 \mathrm{~m}$ (vertical distance from the channel bottom).

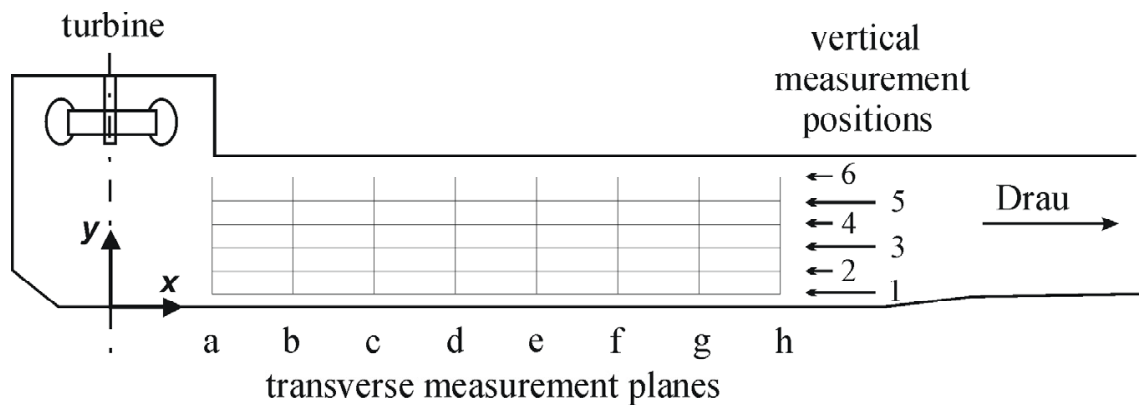

Figure 6: Schematics of measurement points selection. Side view.

Table 1: Distance of measurement planes from the turbine axis. Schematics are shown in Fig. 6 and 7.

\begin{tabular}{|c|c|c|c|c|c|c|c|c|}
\hline $\begin{array}{c}\text { Transverse } \\
\text { measurement } \\
\text { plane }\end{array}$ & $\mathrm{a}$ & $\mathrm{b}$ & $\mathrm{c}$ & $\mathrm{d}$ & $\mathrm{e}$ & $\mathrm{f}$ & $\mathrm{g}$ & $\mathrm{h}$ \\
\hline $\begin{array}{c}\text { Distance } \\
\text { from the } \\
\text { turbine axis } \\
(\mathrm{m})\end{array}$ & 5.915 & 7.915 & 9.915 & 11.915 & 13.915 & 15.915 & 17.915 & 19.915 \\
\hline
\end{tabular}

Table 2: Vertical positions of measurement points. Schematics are shown in Figs. 6 and 7. For the measurement planes e to h, the height of the measuring point 6 is $1.50 \mathrm{~m}$, all distances are measured vertically from the channel bottom.

\begin{tabular}{|c|c|c|c|c|c|c|}
\hline Vertical measurement position & 1 & 2 & 3 & 4 & 5 & 6 \\
\hline Distance from the bottom $(\mathrm{m})$ & 0.25 & 0.5 & 0.75 & 0.1 & 1.25 & 1.4 \\
\hline
\end{tabular}


There were three parallel longitudinal (x-y) measurement planes - middle, left and right measurement plane (Fig. 7). Longitudinal axis of the channel (x) lay in the central $\mathrm{x}-\mathrm{y}$ measurement plane; left and right $\mathrm{x}-\mathrm{y}$ measurement planes were positioned $0.95 \mathrm{~m}$ to the left and right, respectively, from the central $\mathrm{x}-\mathrm{y}$ plane according to the waterflow direction (from turbine to the Drau river). The central $\mathrm{x}-\mathrm{y}$ measurement plane was shifted $0.66 \mathrm{~m}$ to the left due to mounting of the probe as compared to the measurement probe from TUG (Mayr and Arch, [7]). Each longitudinal measurement plane contained $8 \times 6$ measurement points, which were positioned as depicted in Figs. 6 and 7.

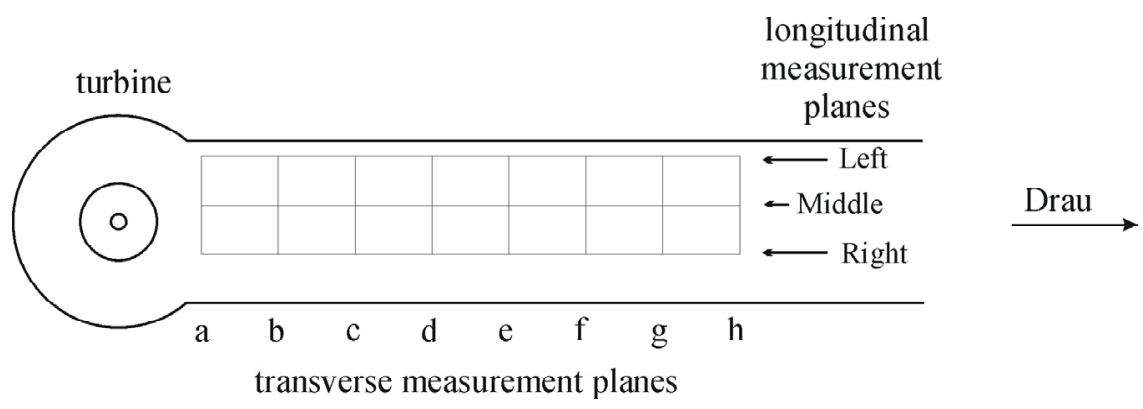

Figure 7: Schematics of measurement points selection. Shown are three longitudinal measurement planes - middle, left and right, top view.

In every measurement point on a particular measurement plane 240 images of the flow were processed. The exposure time was set to $1 / 1000 \mathrm{~s}$.

\section{Results}

Fig. 8 show typical sample images of the two phase flow during measurements taken at each horizontal position $\mathrm{x}$ and at three different vertical positions $\mathrm{y}=$ $0.25 \mathrm{~m}, \mathrm{y}=0.75 \mathrm{~m}$ and $\mathrm{y}=1.25 \mathrm{~m}$.

It is clearly seen from Fig. 8 that the volume void fraction decreases with decreasing height from the bottom (y) and we can expect the same with increasing distance from the turbine vertical axis $(\mathrm{x})$.
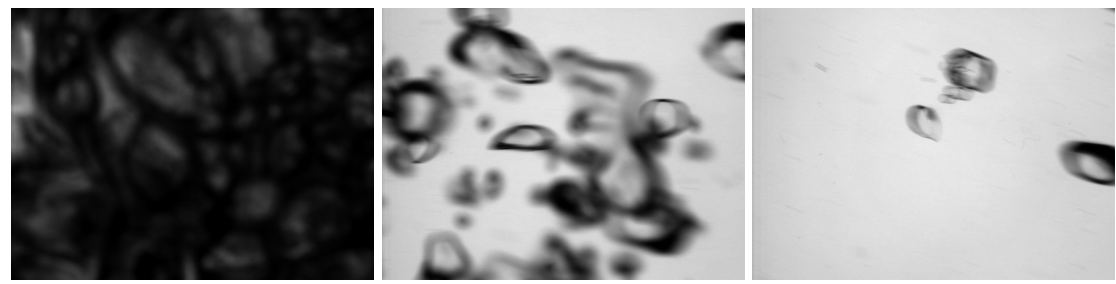

Figure 8: Sample images taken at a transverse measurement plane d, vertical position $y=1.25 \mathrm{~m}$ (left), $y=0.75 \mathrm{~m}$ (middle) and $y=0.25 \mathrm{~m}$ (right). 
From series of consecutive images of two-phase bubble flow structures, the basic variable is presented through time-averaged grey level intensities and appropriate standard deviation of the latter. Equivalent diagrams of void fraction distribution (according to the calibration protocol) were calculated according to the eqn. 6 .

By applying the functional relationship between the measured grey level intensity and the volume void fraction, depicted in Fig. 4, it is possible to obtain similar diagrams for void fraction (Fig. 9).

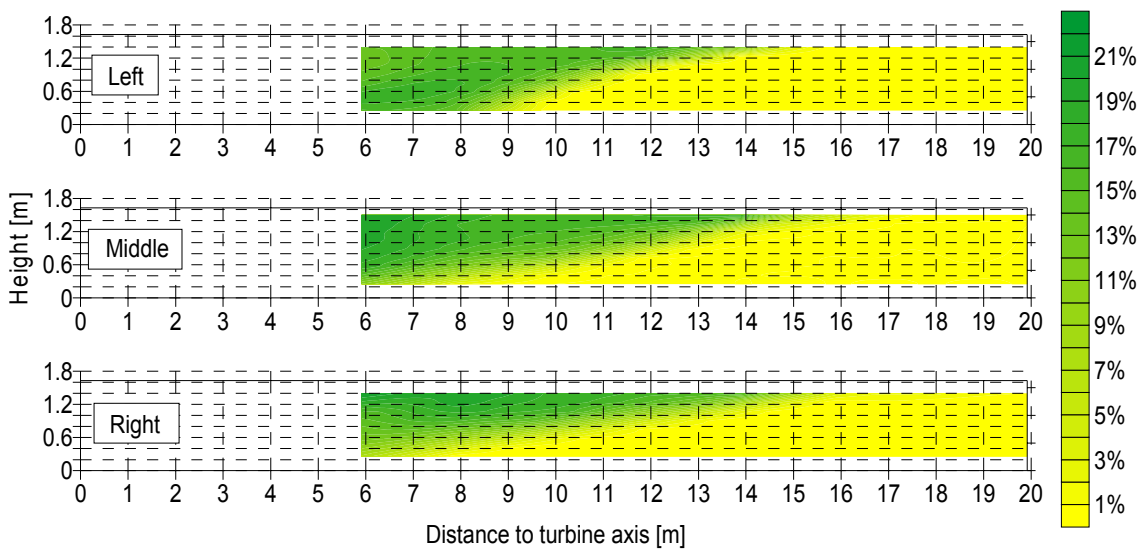

Figure 9: Average volume void fraction.

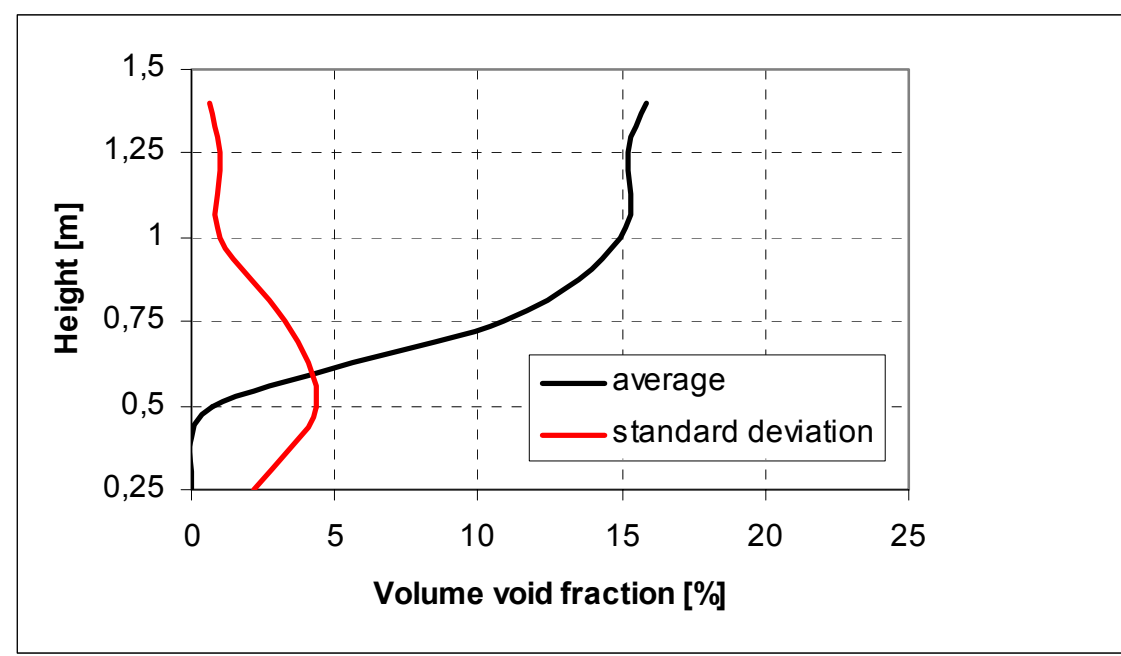

Figure 10: Average volume void fraction and its standard deviation in the transverse measurement plane $\mathrm{c}$ (middle longitudinal measurement plane). 
It can be seen from Fig. 9 that the flow in the outlet channel of the turbine is two-phased up to the distance of approx. 16-17 $\mathrm{m}$ from the turbine vertical axis; from this point on the flow is mainly single-phased (liquid). The two-phase flow exists in the whole transverse section of the channel only up to a distance of approx. 8-9 $\mathrm{m}$ from the turbine veritical axis. Afterwards, the flow stays twophased only in the upper part of the channel due to buoyancy effects. Standard deviation of the average grey level intensity as well as of the volume void fraction (Fig. 10) is the highest in the region of transition from two-phase to single-phase flow.

\section{Conclusions}

The paper describes a visualization method for volume void fraction measurement in the gaseous-liquid flow. The volume void fraction is measured by means of image acquisition via a fast industrial camera and by determination of the average grey level intensity of the acquired images.

The relationship between the average grey level intensity of the images and the void fraction was determined by a calibration procedure at known values of void fraction. It turned out that such a relationship could be described by a simple law, which is based on the exponential function.

Apart from the void fraction measurement it is possible to use the described method for the determination of shape and size of the gas bubbles. By means of statistical processing of the succesive images the assessment of the average bubble direction and their velocity could be achieved at every measuring point (future works). Measurements conducted in the tailwater channel of a Pelton turbine proved the suitability of the described method not only by the comparable results with the other measurement method, but also with respect to robustness, relative simplicity, ease of handling and applicability for operation in industrial environments (hydro powerplants, purification facilities, etc). One of the most important features of the described visualization method is the fact that the volume void fraction can be easily monitored during the operation of the station/facility without the need to stop or hamper the operation of such a facility.

\section{References}

[1] Daidzic, N.E., Schmidt, E., Hasan, M.M., Altobelli, S., Gas-liquid phase distribution and void fraction measurements using MRI, Nuclear Engineering and Design 235, pp. 1163-1178, 2005.

[2] Dong, F., Jiang, Z.X., Qiao, X.T., Xu, L.A., Application of electrical resistance tomography to two-phase pipe flow parameters measurement, Flow Measurement and Instrumentation 14, pp.183-192, 2003.

[3] Hibiki, T., Ishii, M., Experimental study on interfacial area transport in bubbly two-phase flows, International Journal of Heat and Mass Transfer 42, pp. 3019-3035, 1999. 
[4] Hogsett, S., Ishii, M., Local two-phase flow measurements using sensor techniques, Nuclear Engineering and Design 175, pp. 15-24, 1997.

[5] Huang, Z., Xie, D., Zhang, H., Li, H., Gas-oil two-phase flow measurement using an electrical capacitance tomography system and a Venturi meter, Flow Measurement and Instrumentation 16, pp. 177-182, 2005 .

[6] Jaworek, A., Krupa, A., Trela, M., Capacitance sensor for void fraction measurement in water/steam flows, Flow Measurement and Instrumentation 15, pp.317-324, 2004.

[7] Mayr, D., Arch, A., Entgasung von Wasser-Luft-Gemischen in Unterwasserkanälen von Pelton-Wasserkraftanlagen, Österreichische Wasser- und Abfallwirtsch. 11-12, pp. 167-175, 2005.

[8] Sach, L., Angewandte Statistik: Anwendung statistischer Methoden, Springer-Verlag: Berlin,1997.

[9] Stahl, P., von Rohr, P.R., On the accuracy of void fraction measurements by single-beam gamma-densitometry for gas-liquid two-phase flows in pipes, Experimental Thermal and Fluid Science 28, pp. 533-544, 2004.

[10] Trdič, F., Širok, B., Bullen, P.R., Philpott, D.R., Monitoring mineral wool production using real-time machine vision, Real-time imaging 5, pp. 125 $140,1999$. 